\title{
Utilization of Artificial Intelligence in Tax Audit in Indonesia
}

\author{
Siti Kurnia Rahayu* \\ Department of Accounting, Faculty of Economic and Business, \\ Universitas Komputer Indonesia
}

\begin{abstract}
The purpose of the article is to explain the design of Artificial Intelligence (AI) in the tax audit system which includes the existing status of ICT, the possibility of AI adoption in the Tax Administration System, supporting factors, challenges in implementing AI and the readiness of tax auditors in Directorate General of Taxes (DGT) in implementing AI. The research used a qualitative method through interviews with three key informants. The key informants came from the DGT who designed the Information System at DGT and relevant to the Tax Audit, in Jakarta Indonesia. Apart from key informants, the research also included an analysis of several documents issued by the DGT regarding the Information System at DGT. The data analysis used in this research was inductive analysis. The findings indicate that there are challenges to system development synergy at DGT related to the development process by adopting a private sector work style. DGT is still trying to understand the potential benefits of implementing a system with AI due to the novelty of the system and it has not been tested so that the predictions of benefits are uncertain, as well.
\end{abstract}

Keywords: Artificial Intelligence, Tax Audit, Tax Administration System, Directorate General of Taxes.

\section{$\underline{\text { ARTICLE INFO }}$}

\section{Article History:}

Received: 05 May 2021

Accepted:05 October 2021

Available online: 01 December 2021

\footnotetext{
* Corresponding Author: Siti Kurnia Rahayu, Department of Accounting, Faculty of Economic and Business, Universitas Komputer Indonesia, J1. Dipatiukur No. 112 Bandung, West Java, Indonesia; Email: siti.kurnia@email.unikom.ac.id ; Tel: +6281394699986
} 


\section{INTRODUCTION}

The efficiency of tax administration in optimizing tax collection is emphasized in order to minimize taxpayer non-compliance, through tax law enforcement by examining taxpayers who are at high risk of non-compliance, because it is inefficient to routinely carry out audits of taxpayers who are at low risk of non-compliance and conduct audits of compliant taxpayers (CPI, 2018). An optimal tax revenue is something that is impossible to achieve for tax auditors, because controlling, managing and inspecting taxpayers efficiently and effectively requires the use of effective "tools". Artificial Intelligence (AI) has advantages in the tax domain in processing large amounts of tax information and providing sufficient information (Milner \& Berg, 2017). Tax authorities in Australia, Canada, Norway, UK, have developed a model that is supported by AI which can predict high-risk taxpayers for a tax audit, where a taxpayer who is high risk in terms of reacting positively to various tax authority interventions to increase tax revenue (OECD, 2020). Techniques carried out in the analysis using AI refers to the behavioural sciences and also data mining, in developing existing methods by ensuring that large cases that represent the best solutions in tax audits are carried out as a priority (CPI, 2018). The scope of advanced analytics through AI continues to improve in the developed world, where its use has gone beyond the identification of relevant financial and tax cases so that the tax audit carried out by the taxation authority of a country can include a method of documenting the implementation of tax audits with a high degree of certainty, so that the target is complete. Tax revenue through high tax compliance is achieved as a result of an efficient tax audit (Veit, 2019).

Utilization of Artificial Intelligence is predicted to provide a very satisfactory level of service to taxpayers in carrying out their tax payment obligations as well as providing technical and administrative information on taxation policies to taxpayers and also on the internal environment of the taxation authority at a more strategic level (OECD, 2020). The utilization of AI can be done by tax agents and tax auditors to determine a generic model that will be applied in identifying the risk of taxpayers, analysing the results of identification with the data obtained (CPI, 2018). For tax auditors, the usage of analytics through the application of AI can be used in determining tax audit priorities for the results of the generic model analysis which is then carried out for tax audits, and evaluating the results of audits as part of 
the Taxpayer's database recorded within the taxation authority (CPI, 2018). Different types of analytics that can handle this generic model include the Predictive Analytics and Prescriptive Analytics (CPI, 2018).

Predictive analytics seek to anticipate possible problems, so that tax agents can take appropriate precautions (CPI, 2018). The use of predictive analytics in tax audits can determine decision making in choosing tax cases or taxpayers that are more appropriate for tax policy targets, as well as in determining taxpayer segmentation based on certain criteria by using several types of technical data analysis (Hashimzade et al., 2016). Prescriptive analytics helps tax agencies model the impact of actions on taxpayers, so that they can select the most effective actions for a particular sector, segment or case (OECD, 2020). Prescriptive analytics is an effort to look for causal relationships that can be obtained from previously collected taxation data (Veit, 2019).

Evidence from previous research shows that although the state makes use of AI, and the access rights of taxpayers for AI are not clearly regulated, general principles derived from fundamental rights provide the possibility of protecting the rights of taxpayers in accessing information in this system (Faundez et al., 2020). The results of another research showed that AI enables the tax auditor to control the search for solutions and substantial policies that will follow the recommendation of system results, increase access to top management, decrease the need for greater supervision, as well as more work that can be done without supervision, and able to make decisions immediately and at a greater scope (O'Leary \& O'Keefe, 1997). Several studies aim to design and develop AI to be able to predict the risk level of taxpayer fraud in determining tax audits (Zeryhun, 2020). Other research shows that the AI system in the resulting tax domain can detect the sequence of events accurately marking entities and their filings that have the potential for tax evasion in the context of actual tax regulations (Hemberg et al., 2015). The AI system built for imitating the tax auditor's decision process is claimed to increase $63 \%$ of the efficiency of tax audit choices, which shows that the tax audit strategy has been successfully implemented by tax authorities (Hsu et al., 2015).

The research questions addressed were: 1) What is the current condition of the implementation of ICT for tax audit at the Directorate 
General of Tax (DGT)? 2) What is the possibility of developing AI for tax audit at the DGT? 3) What are factors need to be considered in using AI by the DGT and adapted by tax Auditors? 4) What are the challenges faced in adapting AI at the DGT? 5) What is the opinion of tax auditors regarding the readiness of the DGT in the development of AI? The purpose of this study was to provide an overview and explanation of the cognitive meaning related to the five research questions as a phenomenon that occurs in depth, so that it can be used as a basis for the formulation of AI in the field of tax auditing based on the development of ICT sophistication.

This study was prepared as preliminary research to be used as part of the reasons for developing AI for the DGT by using a comparative study of tax authorities in developed countries and in-depth information obtained from related experts at the DGT. Apart from being motivated by the rapid advancement of sophisticated technology in the world what needs to be addressed is the real condition of the information system that has been implemented in Indonesia so far. It is for this reason that it is important to provide views regarding the development of a comprehensive information system in response to the dynamic rate of sophistication in the use of ICT by taxpayers.

\section{LITERATURE REVIEW}

AI is a technology for speech and image recognition, data, semantic analysis and machine learning that requires cost and technical knowledge to adopt with commensurate potential (Chukwuani, 2020). AI is the ability of a device that is programmed according to the human brain; including knowledge, acquisition of knowledge, judgment, original thinking and understanding of relationships, so that as an intelligent machine that responds similarly to humans, it includes intelligence, business, research and programming (Carol \& O'Leary, 2013). AI as a tool to solve business problems is better than human solutions which includes symbolic programming. AI is utilized in problem solving that involves choices with decisions based on logical steps, therefore making AI a potential area to be further explored in business sense (Taghizadeh et al., 2013). AI can be used by auditors to automate tasks that have been done before so that they can focus on improving the quality of their work through advanced analytical evaluations, spending additional 
time to increase knowledge and provide better professional decisions (Greenman, 2017). Recurring tasks of bookkeeping or tasks performed with processes are replaced by automated technology (Greenman, 2017). An important area that makes use of AI is the document review that can be done automatically. This technology with automatic processing is able to identify and extract key terms (Raphael, 2015).

Tax audit is one of the determinants in building the trust of taxpayers to remain in the corridor of tax compliance, so it is important for the DGT to build mutual trust with taxpayers. Tax audit is a series of activities in collecting and managing data, information, evidence that is carried out objectively and professionally based on Audit Standards to test compliance, and/or for other purposes in order to implement the provisions of laws and regulations in the field of taxation. This results in a Tax Collection Letter (STP), Tax Assessment Letter (SKP) or Preliminary Evidence Audit Recommendation as legal certainty for Taxpayers to carry out the audit results. So the audit must be planned in such a way as to be more effective in supporting the optimization of tax revenue (Siti Kurnia Rahayu, 2020:372). Currently, tax auditors use audit support software and DGT's internal database to support and document the entire audit process, such as SIDJP, appportal, approweb, Supervision Summary menu, e-audit Utilities, Tax Audit Management Application (AMPP). In addition, supporting tools for audit activities can also be in the form of Digital Forensic activities jointly between Tax Auditors and Digital Forensic experts in accordance with the provisions concerning Digital Forensic Guidelines for Tax Purposes (Siti Kurnia Rahayu, 2020:403).

The main area of AI is expert systems (Shukla \& Vijay, 2013). An expert system shell is a software programming system that allows the creation of an expert or knowledge-based system that is easy to implement (Chukwuani et al., 2020). Expert systems are the most widely used AI and are programmed to achieve a level of expertise capable of replacing human dominance in certain decision-making areas (Chukwuani et al., 2020). AI is often developed with expert systems shells in mind, so this implies that any field has the specific capabilities required, this is a potential area for expert systems (Chukwuani et al., 2020). Another important area in AI is the neural network, which is a technology that has the ability to connect facts and draw conclusions, which is the core of learning that can be done 
by humans and this is implemented into computer programs (Shukla \& Vijay, 2013). Robotics is a field in AI that involves computer-controlled mechanical devices in performing tasks that require high accuracy or tedious or dangerous work by humans (Shukla \& Vijay, 2013).

A robot is a system of sensors, control, manipulator power supplies and other software that coordinates in carrying out tasks; with the characteristics of sensing, movement, sensing energy and intelligence similar to the human way (Yudkowsky, 2018). In AI, fuzy logic is useful for commercial and practical purposes that can control machines with acceptable reasoning, helping to overcome uncertainties in system design engineering to learn and demonstrate intelligence (Chukwudi, 2018). Fuzzy logic is a method of reasoning that resembles human reasoning by imitating the way humans make decisions, in the form of logic, the truth value of variables can be real numbers (Chukwudi et al., 2018). The communication method with an intelligence system uses natural language, namely Natural Language Processing (NLP), which is the main technology of AI that mimics human natural language with input in the form of speech and written text needed to process data and communicate effectively (Taghizadeh et al., 2013). Intelligent agent technology as a key solution technology for dealing with information overload due to network business development. Intelligent agent is a software that can run a series of operations on behalf of other programs with a certain level of independence and in doing so, uses a degree of independence and knowledge of the intended use or desire (Norman, 2003).

Previous research related to AI in the field of audit as a basis for this research provides support that there is nothing impossible in the application of information systems that adopt AI in the field of taxation. AI is able to change jobs with cloud and block-chain systems to support work and offer increased information security and increased transparency so that highvolume and large-time tasks can be automatically performed (Sora Yoon, 2020). Greenstein \& Morgan's research concluded that the application of an expert system for the proposed auditing can support audit decisions where the potential impact of this system is and the future use of expert systems as a tool for reengineering the audit process (Vasarhelyi \& O'Leary, 2005). According to McEcham \& Zebda, uncertainty in auditing is caused by the ambiguity inherent in auditing. Fuzzy logic as part of AI has the potential to deal with this uncertainty through reduced knowledge acquisition costs, as a 
means to reconcile various expert judgments and a more realistic mechanism and imitate the expert decision-making process (Vasarhelyi \& O'Leary, 2005). McKee's research concluded that the use of the ID3 algorithm can develop a simple bankruptcy prediction model that is consistent with the theory of temporal continuity (Vasarhelyi \& O'Leary, 2005). The adoption of AI can be carried out in an effort to increase its potential in producing a miracle of enormous workloads with the sea of data in the auditing sector (Gusai, 2019).

\section{METHODOLOGY}

This research was qualitative research; which was used to obtain a complete picture of the assignment in the tax auditing field from the user's point of view regarding the use of AI. This research was designed to provide understanding by captivating the meaning in the field through direct interaction involving the researcher with the tax auditor and also the study of related documents. The data source for this research were key informants consisting of two DGT Auditors, and one DGT Information System Expert, assigned in Jakarta, Indonesia. The determination of data sources in this study was carried out purposively, by adjusting to the problem and research objectives where the informant had knowledge about the required data. The research was conducted from June - August 2020, in Jakarta Indonesia.

Data collection was carried out including rapport creation activities, purposive selection of informants and recording of data collection results. Data collection techniques were carried out with guided interviews and document review. The interview technique was carried out systematically, namely the interview was preceded by the preparation of an interview guide instrument by the researcher. Then the interview was conducted through telecommunication media and recorded. Document review was done by digging up information through facts stored in tax regulations and journals.

The researcher used triangulation data validity testing techniques, in verifying the validity of the data, namely by:

1. Triangulation methods, to compare information so that there were no errors in data collection; 
2. Theory Triangulation, to compare information with relevant theoretical perspectives.

The researcher also used a qualitative-verification analysis strategy by conducting an inductive analysis, which is an approach by drawing general conclusions from real facts in the field. This inductive analysis was carried out throughout the study, with the aim of simplifying the data into a much simpler form. Procedures in the analysis of data obtained included:

1. The performance of data reduction, by selecting data that was relevant to the research, and giving attention to the main problems in the research.

2. Presentment of the summarized data in descriptive form.

3. Drawing conclusions to provide solutions for problem solving.

\section{RESULTS AND DISCUSSION}

\section{Current Condition of ICT Implementation in the DGT Environment}

Current development of ICT in the DGT related to tax audit includes Social Business and Big Data Analytics. Social Business is a pillar that confirms that the data and information needed by the tax auditor includes formal and informal sources in exploring tax potential. Big Data Analytics was intended to strengthen Analytics through the use of Big Data, to facilitate the success of the process through extracting tax potential and preventing tax evasion because of the many patterns and correlations of tax data obtained.

The results of identification for the progress of application development used for the tax audit:

1. Compliance Risk Management Application. Applications have been used to determine the priority of compliance objects through compliance risk management (CRM). The compliance map in the CRM for the audit as function illustrates the risk of taxpayer compliance in reporting, payment and its correctness based on the level of noncompliance and the level of taxpayers' contribution to tax revenue. 
This application was one of the tools for Institutional Transformation to determine the risk profile of taxpayers so that tax audits are more focused and taxpayers are segmented based on risks. This CRM used a risk engine from the internal and external data obtained by the DGT. This differentiation of taxpayers based on compliance risk was the basis for developing a Risk Engine in the CRM so that taxpayers can be mapped systematically according to best practices in the world of international taxation that are measured based on scores and risk weights and objectively based on data. The basic risks that affect tax compliance in this CRM application are the risks of registration, reporting, payment and the accuracy of reporting. The implementation of CRM for tax audits in SIDJP contains a Compliance Map and a List of Potential Mining Priority Targets to determine specifically a list of taxpayers who will be extracted tax potential (SE-24/PJ/2019).

2. Analytics Application. A data utilization design framework has been prepared in the form of identification, ensuring data quality, mapping data, comparing internal and external data, and providing it in the Taxation Information System to produce reliable and accurate data. Application development is currently at the stage of architectural policy formulation and tax data analysis process. By using an international scale quality platform, tax potential can be extracted without waiting for application development time. Applying analytics applications to the entire process allows the execution of extracting data from the taxation software database and automating the analysis to determine the system is delivering the desired results. Application users can view high-level snapshots of possible coding or calculation errors in various data groupings. This tool allows tax auditors to prepare for potential audits and more effectively

3. Data Quality Application. The Matching Data (Data Quality Service) application has been refined. Application performance achieves optimal results, and is equipped with the necessary functions to connect data obtained from third parties with taxpayer data.

4. SIDJP NINE Application. SIDJP NINE is an application for processing taxpayer transaction data starting from registration, reporting, tax payment which was integrated with the main tax administration 
modules and the DGT internal database. According to the tax auditor, SIDJP NINE's performance was satisfactory because it is able to provide information according to the needs of tax audit activities. SIDJP NINE performance national is much better than previous applications and this was due to the support of communication networks, server capacity and the condition of the application itself with the Java platform.

5. Data \& Information Exchange Application. The identified external data was realized at $68 \%$ of the target of $65 \%$ (LAKIN DJP, 2019), in the form of data that has been received by the DGT External Data Management Sub-Directorate.

6. Document Management Application. The completion of the digital transformation program had reached 97\% (Year 2019). Document Management application is an information system application that is used to store, track, manage electronic documents, electronic images of paper-based information through document imaging.

The results of data processing sourced from DGT documents on ICT implementation related to tax audit can be seen in Table 1.

Table 1: Application and Data Needs Related to Tax Auditing in DGT

\begin{tabular}{|c|c|c|c|}
\hline No & Application & $\begin{array}{l}\text { Supporting Data for } \\
\text { Application }\end{array}$ & Platform Application \\
\hline 1 & $\begin{array}{l}\text { Compliance } \\
\text { Risk } \\
\text { Management }\end{array}$ & $\begin{array}{l}\text { All data to determine the level of } \\
\text { taxpayer risk compliance }\end{array}$ & $\begin{array}{l}\text { Data Management; Transaction } \\
\text { Processing Security; User } \\
\text { Interface }\end{array}$ \\
\hline 2 & Analytics & $\begin{array}{l}\text { All historical data resulting from } \\
\text { transactions that are inputted } \\
\text { into the data warehouse }\end{array}$ & \\
\hline 3 & Data Quality & $\begin{array}{l}\text { Taxpayer data and data } \\
\text { exchange results that have } \\
\text { gone through a matching } \\
\text { process }\end{array}$ & $\begin{array}{l}\text { Data Interchange; Transaction } \\
\text { Processing, Security, System } \\
\text { \& Network Management. }\end{array}$ \\
\hline
\end{tabular}


4 SIDJP NINE

5 Data \& Information Exchange

6 Document Management
Taxation data which includes Registration Data, Payment Data, Reporting Data, Supervision Data, Audit and Investigation Data, Billing Data, Objections and Appeals Data, Service Data, Intensification Data and PBBP3 Data

Data from third parties and from P3B partner countries

SPT Image Data, Legal Product Data, Inspection Result Data, Correspondence Data
Software Engineering: Data Management; User Interface; Location \& Directory; Transaction Processing; Security; Software Engineering; System \& Network Management; Network Services.

Data Interchange; Transaction Processing, Security; System \& Network Management.

Graphics \& Image; Backup \& Restore; Data Interchange; User Interface; Location \& Directory; Software Engineering; System \& Network Management; Network Services.

Source: PER - 46. PJ_2015

The results of identification for the infrastructure application used by tax audit were as follows:

1. Master Data Management. Based on the inductive analysis carried out in this study were:

a) Data Quality Monitoring of IT infrastructure at the DGT cannot be done easily by system data analyst, because the master data has not been managed properly in all applications, and the master data was still scattered in different application databases. Data access management was still carried out in each application, the master data had not been consolidated because the policies and procedures were not in accordance with the needs of users of each of the DGT organizational function. The accuracy and performance of the process for identity matching were still not optimal in ensuring the quality of information required by system users.

b) The certainty and clarity of data ownership structure still needed to be improved, where the ownership of data in the master entity was still uncertain, the clarity of the person in charge and how the solution was to solve the correct data findings. In business 
processes an organizational unit is needed as a decision maker to build effective data governance. The inherent challenge in this case was good communication skills which can support DGT's IT development capabilities in managing data to reduce data overlap and convoluted bureaucracy. Communication skills must be maintained in order to maintain stakeholder commitment and maintain clarity of data ownership structures. The importance of good data management will be able to formulate a good understanding of data policies in the system being implemented and this will provide added value. Data accountability still needed to be improved by intensifying data management, starting with data quality and procedures.

c) Mapping the information needs of decision makers was considered sufficient to provide an objective perspective for the quality of current DGT data. The quality of master data currently varied between users of information from processing data through all DGT IT applications. DGT's system application management enables data progress to be tracked and used as a basis for decision making. Master Data Management was felt to provide benefits for the management of a larger business process with a greater scope. Master Data Management was still focused on the trend of the IT mindset. It is necessary to follow up on the idea that business problems must be explained by IT. The MDM can provide problem solving solutions related to DGT business processes. As a result, it is critical to prioritize the transformation of modern organizations over the development of technical IT architectures.

2. Enterprise Data Warehouse. The development of the EDW implementation still requires a few changes:

a) Source of data required. DGT utilizes Open-Source Intelligence from cyberspace and has data from third parties obtained from data exchange cooperation in the form of information on share ownership, investors, export imports, auction winners, ownership of securities and ownership of luxury vehicles (PMK No.39/PMK.03/2016). DGT has required banks / credit card 
administering institutions to provide detailed tax data (PMK No.39/PMK.03/2016). There have been collaborations with SOEs in profiling taxpayers through a more comprehensive Big Data, Data Analytics and more up-to-date Business Intelligence. The integration of tax data includes the exchange, processing, research, and testing of tax data through information technologybased means that can reduce administrative burdens that must be borne by taxpayers to comply with tax regulations.

b) Process of Extract, Transform and Load (ETL), and the development of tools for processing data in aggregate (OLAP) and production of analysis reports for decision- making.

3. Cloud Computation. The use of cloud services can transfer the burden of ownership and management of the IT infrastructure to the cloud service.

4. DC-DRC. Recovery of damaged devices inside DC can be done if the DRC has a condition similar to DC. There's a need for DC synchronization with DRC.

Applications of Information Systems used by The DGT tax audit are in a different quadrant by The Mac Farlan Strategic (Table 2).

Table 2: The Mc Farlan Strategic Grid Application Quadrant

\begin{tabular}{llll}
\hline No & \multicolumn{1}{c}{ Quadrant } & Application & \multicolumn{1}{c}{ Information } \\
\hline 1 & $\begin{array}{l}\text { Strategic (Application that are } \\
\text { able to change the direction } \\
\text { of policies and operational } \\
\text { activities with the aim of } \\
\text { optimizing tax revenue) }\end{array}$ & Analytics & $\begin{array}{l}\text { Applications to analysis data through } \\
\text { identifying certain patterns in the } \\
\text { related data, such as application } \\
\text { of data mining for tax data analysis } \\
\text { so that it can identify patterns of tax }\end{array}$ \\
& Data Quality & $\begin{array}{l}\text { Evasion or Tax Avoidance } \\
\text { Applications to ensure the quality } \\
\text { of tax data, especially the quality } \\
\text { to third party data, so that data that } \\
\text { are obtained from third parties can } \\
\text { be linked with the correct data of } \\
\text { the Taxpayer }\end{array}$ \\
& &
\end{tabular}


High Potential (Applications that have the potential to increase tax revenue)

Key Operational (a must have application to run key business processes effectively and efficiently)

Support (Applications used to increase the effectiveness and efficiency of DGT operational activities public)
Compliance
Risk
Management

Information

Systems

DGT New

Improved

Novelty

Excellence

(SIDJP

NINE)

Data \& Information

Exchange

Document

Management
Applications for risk-based supervision, which displays the level of risk to taxpayer compliance, supervision is more appropriate because it is directed at taxpayers with high compliance risk.

Applications that support various DGT business processes which include Registration, Payment, Reporting, Supervision, Inspection, Investigation, Billing, Objection, Appeals, Services, Intensification, PAP3D, Accounting \& Reporting, General Ledger, and Compliance Performance System.

Applications for data exchange with third parties that have collaborated with the DGT and data exchange with partner countries of the Double Taxation Avoidance Agreement.

Applications to manage taxation documents physically and electronically in the form of SPT, tax law products and other supporting documents.

Source: PER - 46. PJ_2015

\section{Possibility of developing Artificial Intelligence for Tax Audit at DGT}

$\mathrm{AI}$ is an approach used in developing software that relies on the concept of human thinking in understanding and deciding and providing recommendations with large-scale parallel computing resources, integrating algorithms, Big Data, Cloud Computation and Sensory Interfaces (Milner $\&$ Berg, 2017), so that with the convergence of computers that are faster better networks can be utilized to improve the quality of tax audits.

AI can be used in analysis data on the track record of taxpayers and other external information to classify the risk of non-compliance. The tax auditor can improve the efficiency of the Taxpayer's Low Risk Score grouping for inspection. This can avoid spamming of taxpayers who ignore tax payments, and may develop tax auditor intervention. The use of AI in routine tax audit tasks allows prediction of potential non-compliance in reporting income and countering tax avoidance. AI is also built to predict 
company bankruptcy, describe the health of a company's business, classify taxpayers' similarities, help reveal complex VAT fraud that reaches many actors, and to analysis larger and more complex data (OECD, 2020). With the infrastructure and application resources that the DGT has, it is not impossible that the utilization of AI can be done in responding to the challenges on the development of advanced technology.

The application that has been used by the tax auditors is currently able to predict tax audits based on the level of compliance risk with internal data management and external data. Adoption of AI can further model the prediction of taxpayer compliance risks and detect any sophisticated taxpayer avoidance and smuggling strategies. With the use of AI computing applications have become deeper and broader in understanding tax data for decision-making for the implementation of tax audits, due to the advantages of computer algorithms that are more transparent, easy to understand for each function, very detailed, has superior speed and consistent results. The orientation of AI to the objectives is a relevant approach in tax auditing because it optimizes utility functions, where the purpose of tax audits is to test taxpayer compliance which has an impact on tax revenue with the legal framework and regulations of the tax law which are often assumed to be not as clear and as definite as a mathematical solution.

AI can be used as a data platform and data analysis in the Analytics application and the Data Quality application which are continuously being developed by the DGT. With this platform, reporting is much greater because it is able to obtain internal and external data and the analyses is much better in finding data differences in tax reporting by taxpayers. In addition, it is able to manage data related to transfer prices, inconsistencies in filing tax documents and tax supporting data for the purpose of increasing numbers of tax audits. Likewise, the frequency of reporting Sales Tax (VAT) is close to real time.

With the number of developments of the AI platform in the tax domain that have been carried out by researchers around the world, the DGT can choose without the need to develop it themselves. DGT can choose based on objectives, required data, problems encountered, experience and historical tax data and existing guidelines. The main possible categories (Milner \& Berg, 2017) that can be applied in the DGT tax audit function in this case are as follows: 
1. Expert Support System. AI is used to answer detailed questions and solve complex problems. This reasoning system is used to make decisions using tax regulation data through a question-matching mechanism, tracing existing tax knowledge data from tax expert information in the system, resolving conflicts and ambiguities that may arise, and finally answering questions while updating the system knowledge base and making improvements from tracing and corrections from tax experts. This system can also compile a very large tax information knowledge base with Deep Query, either sourced from text or images from the internet.

2. Optical Character Recognition (OCR). Data can be input through text recognition and numbers on scanned printouts, then matched with existing image libraries in a short period of time with much better quality, high accuracy without requiring reconciliation. With Big Data access, the tax auditor can use this system for searching and managing data.

3. Natural Language Processing (NLP). AI can automate the identification of meanings in text, understand well the regulations and legal rules with a high level of document complexity and be able to identify meanings where references are found in other documents. The NLP system identifies meaning in depth by integrating linked tax documents via direct reference or through the same subject type, with a language processor for reading complex sentence structures. A detailed document search can also be activated quickly.

The use of Big Data Analytics to predict fraudulent taxpayer behaviour is the main target of the DGT. Tax Analytics and Compliance Risk Management applications and Document Management applications have been developed in the process of refining the DGT's ICT strategy. The development of an open Application Programming Interface (API) requires an open platform with the aim of improving and ensuring that data from third parties can enter the DGT system through technology owned by third parties. During the development and algorithm development process of these applications it is also possible to adopt the utilization of AI as a development platform. 


\section{Supporting factors for the use of Artificial Intelligence}

Important factors for the development of AI:

1. Factors in the implementation of project design and investment planning.

a) Defining precise design objectives. Development projects must provide value and be recognized by all levels of management in the organization. It is important to design collaborations between systems and a team of experts, and measure speed, accuracy and efficiency at their respective strengths.

b) Data relevant to the expected results. Taxpayer business data collection includes external data that has not been imported from the past tax function regularly and repeatedly.

c) Rapidly integrate upstream to downstream AI design.

d) Data science expert on the project team. These specialists are rare and expensive but indispensable for solutions to very profound problems.

2. Development of Tax Auditor Resources and Job Interruptions. There are not many tax auditors who are skilled and experienced in encouraging the development of AI-based information systems, so that it can become an inhibiting factor in the initiative. Solutions can be addressed through building development teams within the organization or providing vendors with specialized expertise. If AI is built inhouse, it is important to carry out surveillance by a dedicated team by optimizing the functions of the specialist, minimizing the involvement of large numbers of people and the importance of published progress reviews. Leadership with predictive data and analytical expertise is essential in model building at every design stage.

3. Data Access. Utilizing AI requires tax-relevant Big Data:

a) Public Data; publicly available data.

b) Data from one large company, if the analysis remains valid within the company.

c) Business Simulation Data, the use of specific company data to build a general applications model for use outside the company. Simulation data is used to overcome data privacy restrictions, 
and AI models provide an alternative when access to tax data is restricted.

4. Privacy. The new tax policy needs to be adjusted regarding business data, both financial data and non-financial data that can be accessed, how the data can be used and how the data can be sent.

5. Regulations, laws and government policies. Tax law systems and other related laws need to discuss the implications of implementing AI. The implication is in the form of obligations between jurisdictions, data providers and clients regarding the person in charge of providing financial advice, system developers, operators and AI users themselves.

Infrastructure and personal expertise at tax authorities can engage IT vendors with an open-source software with veneers or their own user interfaces. The DGT can use its in-house developer to create a similar prototype with connections with small start-ups as needed. It is more efficient to have in-house proof-of-concept prototype with a large capacity.

\section{Challenges faced in adapting Artificial Intelligence in DGT}

Adapting this smart application requires a capable competency framework. So far, tax auditors have not been fully equipped with advanced analytical skills using AI in the form of much more modern technical analysis. It is important to give the next generation of tax auditors the skills to work with large-scale, heterogeneous and multi-structured data by using large memory tools and distributed computing architectures. These competencies should emphasize an interdisciplinary approach that includes knowledge of the tax domain and communication skills.

Another obstacle that is likely to occur is job analysis and classification, where the human resources are not sufficient to meet in-depth data analytical skills. The future tax examiner workforce will require audit core education as well as advanced data analytic skills and artificial intelligence. Analytics training for the tax auditors cannot easily be provided, it is important to increase the opportunities of temporary assignments in understanding data analytics with AI, take part in ongoing analytics workshops and training. In attracting the talent of young tax auditors required for advanced analytical 
competence is to provide an annual Fellowship Program and be given an income commensurate with the skills and experience possessed with a minimum requirement of a bachelor's degree. This is to ensure that young examiners at the manager level have access to professional development in studying the relevance of data, technology and advanced analytical methods needed to form strategies for achieving DGT goals.

Top leadership in organizations poses a major challenge required for the current competitive analytical talent landscape in DGT, not just for the bureaucratic functioning of the government. In implementing information systems by utilizing AI priority should given to leaders who have expertise in statistics, learning about information machines, information system architectures and modern computing software. In addition, leaders should have deep knowledge in the application of advanced analytics and artificial intelligence in the field of taxation.

\section{The Tax Auditor's Opinion Regarding the DGT's Readiness in Utilizing Artificial Intelligence}

Tax auditors in the DGT environment face the same challenges as tax auditors in global taxation authorities. There are issues with data analytics that are related to identifying relationships that are not visible in the complex business structure of taxpayers. The presence of multi-party transactions is an essential component of Tax Audit Techniques that must be performed with large amounts of data and limited time. The problem of reporting hidden financial data related to taxes and detecting anomalous data in the Taxpayer's SPT and in a sophisticated Taxpayer Information System is also an important part of implementing tax audits that have not been optimally handled. The handling of the classification of multi-transactional taxpayer problems through many cases still needs to be maximized in its management in order to obtain risk-based objectives in tax audits.

Administrative management before and after an audit is carried out related to the determination of the audited taxpayer and the results of the examination are quite good, but handling it through an application by utilizing AI will only require a short time. The applications that have been built by the DGT in monitoring and inspection functions by utilizing AI can be more effective and efficient in managing large, heterogeneous and 
multi-structured data problems. With the emergence of views in dealing with Big Data and sophisticated computational models, it is necessary to address the use in a continuous process to overcome problems in data management for the field of tax audits.

The Compliance Risk Management application that has been implemented and continues to be developed by the DGT as a taxpayer noncompliance detection model can continue to be developed with a platform as sophisticated as AI in the context of non-compliance that appears without prior historical data related to tax payments. The Data Analytics application can be developed to become a tool capable of providing tax audit decisions related to taxpayer data based on business structures. This sophisticated tool, can be done by classifying the business substructure into smaller, different sub-structures; determining the probability of tax payments as a determining factor, measuring factors that drive prediction of taxpayer problems, making predictions of subsidiary problems and taxpayer ownership structures, and determination of the problem of prediction is permanent or temporary. This requires qualified internal and external Big Data management to be analysed and researched. Data sources such as tax returns, taxpayer accounts, historical tax compliance and case management systems in taxation are internal Big Data type of data that need to be managed quickly and precisely.

\section{CONCLUSION}

DGT focuses on efforts to understand the potential benefits of using ICT, however more specifically for the potential use of AI because there are many new things that have not been tested so the benefits have not been predicted with certainty. It is important to assess the estimated benefits as well as savings through accessing case solutions relevant to the planned models. It is also important to assess new software investments for AI utilization using historical information regarding potential benefits to minimize the risk of implementation losses. On-going application development can be continuously directed at the AI platform through a study of its analytical computing infrastructure to keep pace with the ongoing growth of Big Data. Full development with the use of state-of-the-art computing is essential to prepare training and skills for an open workspace. Future studies can be carried out in the form of a feasibility analysis of medium and long-term 
policies in the application of AI for tax audits. Future studies can use the pillars of mapping, anticipation, timing, deepening, alternative creation and transformation. Through a structured method with this conceptual framework, new strategies can emerge to achieve the target of implementing $\mathrm{AI}$ in tax audits.

\section{REFERENCES}

Carol, E., and $\mathrm{O}^{\circ e}$ Leary, D. (2013). Introduction To Artificial Intelligence And Export System. Retrieved from http://www.mbsfile03.uscredu/ dialtalmeasures.

Chukwuani, V N. (2020). Automation of Accounting Process: Impact of Artificial Intelligence. International Journal of Research and Innovation in Social Science (IJRISS), 4(8), 444-449.

CPI (Centre for Public Impact). (2018). Artificial Intelligence in Taxation Case Study on the use of AI in Government. A BCG Foundation. Retrieved from https://resources.centreforpublicimpact. org/production/2019/01/CPI-AI-Case-Study-Taxation.pdf.

Faundez, A U., Silva M R., Lizana, E A. (2020). Use Of Artificial Intelligence By Tax Administrations: An Analysis Regarding Taxpayers' Rights In Latin American Countries. Computer Law \& Security Review, 38, 105441.

Greenman, C. (2017). Exploring the Impact of Artificial Intelligence on the Accounting Profession. Journal of Research in Business, Economics and Management, 8(3), 1451-1454.

Gusai, OP. (2019). Robot Human Interaction: Role of Artificial Intelligence in Accounting and Auditing. Indian Journal of Accounting (IJA), 51(1), $59-62$.

Hashimzade, N., Myles, G D., Rablen, M D. (2016). Predictive Analytics and The Targeting of Audits. Journal of Economic Behavior and Organization 124, 130-145. 
Hemberg E., Rosen J., Warner G., Wijesinghe S., O'Reilly Una-May., (2015). Tax Non-Compliance Detection Using Co-Evolution of Tax Evasion Risk and Audit Likelihood. Proceeding of the 15th International Conference on Artificial Intelligence and Law (ICAIL), 79-88.

Hsu, K.W., Pathak, N., Srivastava, J., Tschida, G. and Bjorklund ,E. (2015). Data mining Based Tax Audit Selection: A Case Study of a Pilot Project at the Minnesota Department of Revenue, in Real World Data Mining Applications, Annals of Information Systems, 17. DOI 10.1007/9783-319-07812-0_12.

Milner, C., \& Berg, B. (2017). Tax Analytics Artificial Intelligence and Machine Learning-Level 5. PwC Advanced Tax Analytics \& Innovation. Retrieved from https://www.pwc.no/no/publikasjoner/ Digitalisering/artificial-intelligence-and-machine-learning-final1.pdf.

Norman, D. (2003). The invisible computer. The MIT Press, Cambridge, M. Retrieved from:https://www.nngroup.com/books/invisible-computer/.

OECD. (2020). The Impact of Big Data and Artificial Intelligence (AI) in the Insurance Sector. Retrieved from www.oecd.org/finance/Impat-BigData-AI-in-the Insurance-sector.htm.

O'Leary, E D., and O'Keefe, R M. (1997). The Impact of Artificial Intelligence in Accounting Work: Expert Systems Use in Auditing and Tax. AI \& Soc, 11, 36-47, 91997. Springer-Verlag London Limited. DOI: 10.1007/BF02812437. Source: dx.doi.org.

Raphael, J. (2015). How Artificial Intelligence Can Boost Audit Quality. Retrieved from CFO.com.

Shukla, S., Jaiswal, V. (2013). Applicability Of Artificial Intelligence In Different Fields Of Life. International Journal of Scientifc Engineering and Research (IJSER), 1(1).

Siti Kurnia Rahayu. (2020). Perpajakan, Konsep, Sistem dan Implementasi. Rekayasa Sains, Bandung. 
Taghizadeh, A., Pourali, M., Shidfar, D., \& Mirzapour, J. (2013). Artificial Intelligence, Its Abilities and Challenges. International Journal of Business and Behavioral Sciences, 3(12).

Vasarhelyi, M., and O'Leary, D. (2005). Artificial Intelligence in Accounting and Auditing: Adding Value to Business. Vol. 5. Princeton, NJ: Markus Wiener Publishers.

Veit, A. (2019). Swimming Upstream: Leveraging Data and Analytics for Taxpayer Engagement - an Australian and International Perspective EJournal Tax Res., 16(3), 474-499.

Yoon, S. (2020). A Study on the Transformation of Accounting Based on New Technologies: Evidence from Korea. Sustainability, 12(8669), 2-22.

Yudkowsky, E. (2008). Artificial Intelligence as A Positive and Negative Factor in Global Risks. Miri Machine Intelligence Research Institute, Cikovic. New York Oxford University Press. 308-345. (Retrieved from https://intelligence.org/files/AIPos NegFactor.pdf.

Zeryhun, C. (2020). Developing Tax Payer Fraudulent Risk Level Prediction Model for Auditing Using Hybrid Machine Learning Techniques. DSpace Repository, DSpace Institution's institutional repository Retrieved From http://hdl.handle.net/123456789/11281.

SE Dirjen Pajak Nomor SE-24/PJ/2019. Tentang Implementasi Compliance Risk Management dalam Kegiatan Ekstensifikasi, Pengawasan, Pemeriksaan dan Penagihan di DJP.

Laporan Kinerja (LAKIN) Direktorat Jenderal Pajak (DJP) Tahun 2019.

Peraturan Direktorat Jenderal Pajak Nomor PER - 46. PJ_2015. Cetak Biru Teknologi Informasi dan Komunikasi DJP Tahun 2015-2109.

Permenkeu No.39/PMK.03/2016 Tentang Rincian Jenis Data dan Informasi serta Tata Cara Penyampaian Data dan Informasi yang berkaitan dengan Perpajakan. 
